\title{
RANCANG BANGUN SISTEM PENGAMANAN RAK SENJATA M16 MENGGUNAKAN RFID DAN FINGERPRINT
}

\author{
Masno Wibowo, Abd. Rabi', Suprayogi, Irfan Mujahidin \\ Jurusan Teknik Elektro UNMER Malang \\ Departemen Elektronika LEMJIANTEK Malang \\ e-mail: masnowibowo @gmail.com
}

\begin{abstract}
Abstrak
RFID dalam bekerja membutuhkan dua perangkat yaitu yang disebut transponder (tag) atau divais pembawa data dan reader (yang terhubung dengan sistem komputer). Sedangkan Fingerprint menggunakan sensor kapasitif untuk mendeteteksi sidik jari, Salah satu implementasi RFID dapat diterapkan di lingkungan TNI adalah pada sistem pengambilan dan pengembalian senjata M16 di satuan yang memerlukan keamanan dan kecepatan dalam administrasi. Sistem yang akan dibuat yaitu dengan menggunakan jaringan server untuk proses administrasinya, sehingga pemantauan senjata dapat terpusat.
\end{abstract}

Kata Kunci: RFID, Fingerprint, Transponder

\section{Pendahuluan}

Pengamanan senjata merupakan hal yang sangat penting bagi semua satuan prajurit khususnya angkatan darat, baik senjata berat maupun senjata ringan. Pada semua satuan di jajaran TNI-AD proses pengambilan senjata yang berlaku sekarang masih bersifat manual, yaitu setiap personil melaporkan kepada penjaga gudang dan dicatat dengan menggunakan buku besar dan tebal sebagai media untuk administrasi. Dalam hal pengamanan masih menggunakan rantai panjang untuk mengunci seluruh senjata yang ada di rak senjata dengan memasukan rantai pada tempat picu senjata satu per satu[1][2]. Teknologi Automatic Identification (Auto-ID) banyak dikembangkan untuk peningkatan keamanan dan kepraktisan dalam penyimpanan dan pembacaan identitas. Bar Code, Biometric (Fingerprint, Scan Retina), dan Radio Frequency Identification (RFID) serta Smart Card merupakan beberapa contoh dari teknologi identifikasi[3].

RFID menggunakan sistem identifikasi dengan gelombang radio. Untuk itu dibutuhkan dua buah perangkat, yaitu yang disebut transponder (tag) atau divais pembawa data dan reader (yang terhubung dengan sistem komputer)[4][5]. Salah satu implementasi RFID dapat diterapkan di lingkungan TNI adalah pada sistem pengambilan dan pengembalian senjata M16 di satuan yang memerlukan keamanan dan kecepatan dalam administrasi.

Sistem yang akan dibuat yaitu dengan menggunakan jaringan server untuk proses administrasinya, jaringan Local Area Network (LAN). Setiap anggota akan didaftarkan nomor senjata, sidik jari, identitas serta akan diberikan ID card yang identitasnya sudah disesuaikan dengan nomor IP Address yang berbeda sehingga anggota yang satu tidak dapat mengambil senjata anggota yang lain[6][7]. Ketika ada anggota yang akan mengambil senjata maka penjaga gudang hanya membukakan pintu gudang serta mengawasinya saja.

Ketika kartu ID ditempelkan pada reader rak senjata maka senjata akan terbuka kuncinya, sehingga anggota bisa mengambil senjatanya[8][9]. Proses administrasi seperti nama, nomor senjata serta waktu pengambilan akan langsung secara otomatis tercatat di server, sehingga tidak perlu mencatat pada buku gudang. Demikian pula ketika mengembalikan senjata, anggota mengunci senjatanya kembali dengan menempelkan kartu pada reader rak senjata atau dengan fingerprint. 


\section{Metode penelitian}

Perencanaan pembuatan alat pengaman rak senjata terdiri dari perancangan perangkat keras (hardware) dan perancangan perangkat lunak (software).

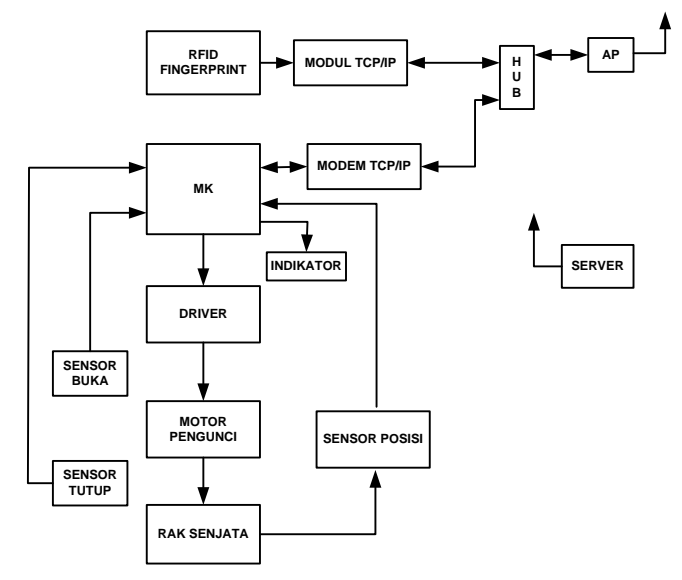

Gambar 2.1 Blok Diagram Sistem Alat.

Diagram blok dalam Gambar 3.1 dapat dijelaskan sistem kerja alat sebagai berikut:

a. ID Card yang masih belum berisi data di daftarkan ke petugas gudang senjata untuk dilakukan proses pengisian data ke dalam server yang berupa nama, pangkat, dan NRP serta nomor senjata.

b. Sidik jari personil di daftarkan ke petugas gudang senjata untuk dilakukan proses pengisian data ke dalam server yang berupa nama, pangkat, dan NRP serta nomor senjata

c. Untuk proses peminjaman senjata, User membawa tag ID Card dan ditempel ke reader kemudian reader mengirimkan perintah ke PC untuk diproses dan diverifikasi. Atau dapat juga User menempalkan ibu jari kanan untuk proses pengambilan senjata.

d. Hasilnya akan dikirimkan ke rangkaian driver untuk menggerakkan motor DC yang digunakan sebagai kunci dan PC untuk menampilkan data pengambilan senjata yaitu nama, pangkat, NRP, dan jam pengambilan senjata.

e. Untuk proses pengembalian senjata User meletakkan senjata terlebih dahulu di rak senjata karena kondisi kunci dalam keadaan terbuka.

f. Selanjutnya User menempelkan ID Card ke reader atau dengan menempalkan ibu jari kanan kemudian reader akan mengirim perintah ke PC untuh diproses dan diverifikasi.

g. Hasilnya akan dikirimkan ke rangkaian driver untuk menggerakkan motor DC yang digunakan sebagai kunci dan PC untuk menampilkan data pengembalian senjata yaitu jam pengembalian senjata.

h. Sensor posisi digunakan sebagai indikator rak ada atau tidaknya senjata, sehingga bila tidak ada senjata di rak kunci selalu dalam keadaan terbuka serta tidak bisa ditutup. Atau sebagai pengamanan apabila ada pembukaan paksa senjata dan pencurian alarm akan berbunyi[10][11].

i. Semua komponen terintegrasi server melalui jaringan LAN dengan modul TCP/IP sehingga sistem pengawasan dan administrasi senjata terpusat.

Komponen utama pada rangkaian ini adalah mikrokontroler, karena komponen ini sebagai otak dari semua kegiatan yang ada. 


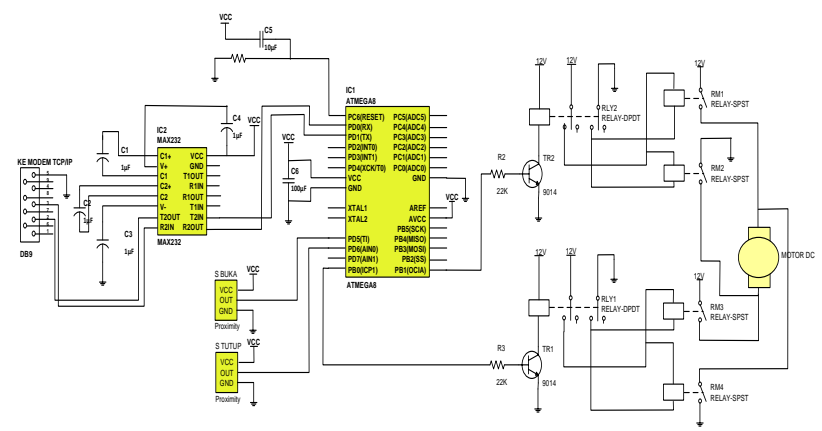

Gambar 2.2 Rangkaian Keseluruhan

Data flow diagram (DFD) menggambarkan komponen-komponen sebuah sistem, aliranaliran data dimana komponen-komponen tersebut, asal, tujuan dan penyimpanan data. Data flow diagram (DFD) menjelaskan hubungan antara produsen data dan konsumen data dengan sistem[12][13]. Hubungan antara produsen data dan konsumen data dengan sistem aplikasi digambarkan pada Data flow diagram (DFD) level 0.

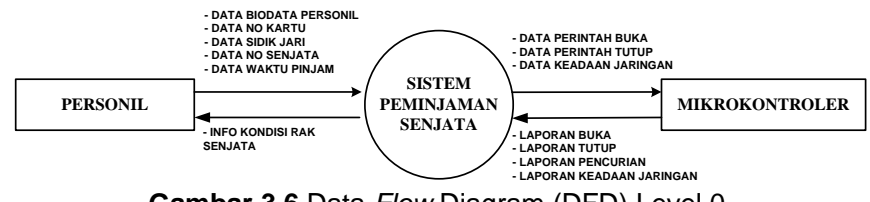

Gambar 3.6 Data Flow Diagram (DFD) Level 0.

ERD (Entity Relationship Diagram) merupakan teknik yang digunakan untuk memodelkan kebutuhan data dari suatu organisasi, biasanya oleh sistem analis dalam tahap analisis persyaratan proyek pengembangan sistem.

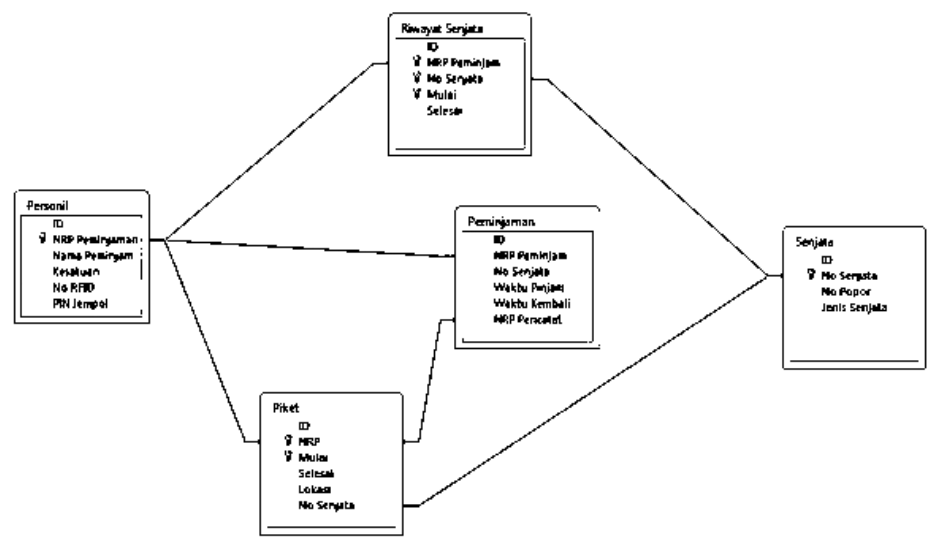

Gambar 2.3 Entity Relationship Diagram.

Perencanaan pembuatan alat pengaman rak senjata terdiri dari perancangan perangkat keras (hardware) dan perancangan perangkat lunak (software)[14]. 


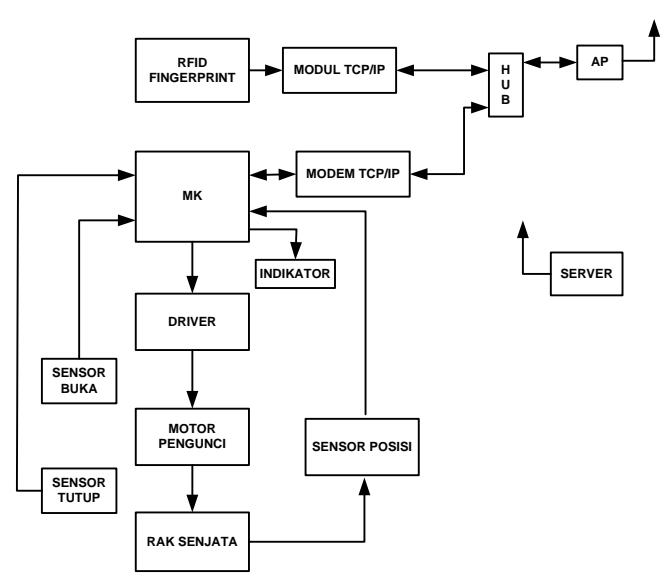

Gambar 2.4 Blok Diagram Sistem Alat.

Diagram blok dalam Gambar 2.4 dapat dijelaskan sistem kerja alat sebagai berikut:

j. ID Card yang masih belum berisi data di daftarkan ke petugas gudang senjata untuk dilakukan proses pengisian data ke dalam server yang berupa nama, pangkat, dan NRP serta nomor senjata.

k. Sidik jari personil di daftarkan ke petugas gudang senjata untuk dilakukan proses pengisian data ke dalam server yang berupa nama, pangkat, dan NRP serta nomor senjata

I. Untuk proses peminjaman senjata, User membawa tag ID Card dan ditempel ke reader kemudian reader mengirimkan perintah ke PC untuk diproses dan diverifikasi. Atau dapat juga User menempalkan ibu jari kanan untuk proses pengambilan senjata[15][16].

m. Hasilnya akan dikirimkan ke rangkaian driver untuk menggerakkan motor DC yang digunakan sebagai kunci dan PC untuk menampilkan data pengambilan senjata yaitu nama, pangkat, NRP, dan jam pengambilan senjata.

n. Untuk proses pengembalian senjata User meletakkan senjata terlebih dahulu di rak senjata karena kondisi kunci dalam keadaan terbuka.

o. Selanjutnya User menempelkan ID Card ke reader atau dengan menempalkan ibu jari kanan kemudian reader akan mengirim perintah ke PC untuh diproses dan diverifikasi.

p. Hasilnya akan dikirimkan ke rangkaian driver untuk menggerakkan motor DC yang digunakan sebagai kunci dan PC untuk menampilkan data pengembalian senjata yaitu jam pengembalian senjata.

q. Sensor posisi digunakan sebagai indikator rak ada atau tidaknya senjata, sehingga bila tidak ada senjata di rak kunci selalu dalam keadaan terbuka serta tidak bisa ditutup. Atau sebagai pengamanan apabila ada pembukaan paksa senjata dan pencurian alarm akan berbunyi.

r. Semua komponen terintegrasi server melalui jaringan LAN dengan modul TCP/IP sehingga sistem pengawasan dan administrasi senjata terpusat[17][18].

Komponen utama pada rangkaian ini adalah mikrokontroler, karena komponen ini sebagai otak dari semua kegiatan yang ada.

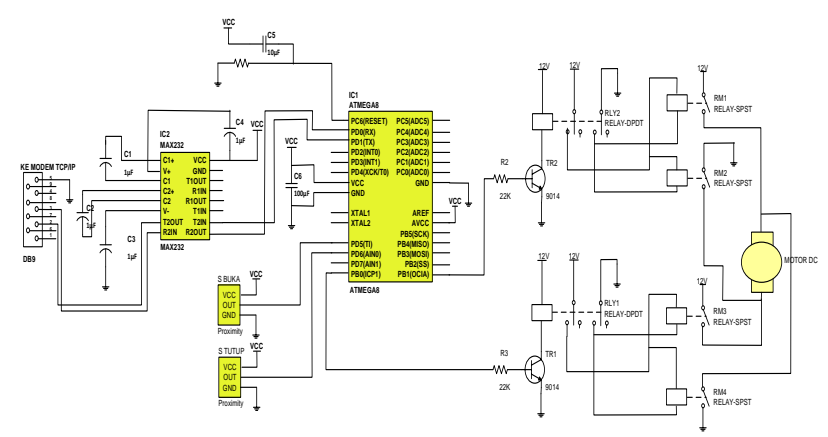


Gambar 2.5 Rangkaian Keseluruhan.

Data flow diagram (DFD) menggambarkan komponen-komponen sebuah sistem, aliran-aliran data dimana komponen-komponen tersebut, asal, tujuan dan penyimpanan data. Data flow diagram (DFD) menjelaskan hubungan antara produsen data dan konsumen data dengan sistem[19][20]. Hubungan antara produsen data dan konsumen data dengan sistem aplikasi digambarkan pada Data flow diagram (DFD) level 0.

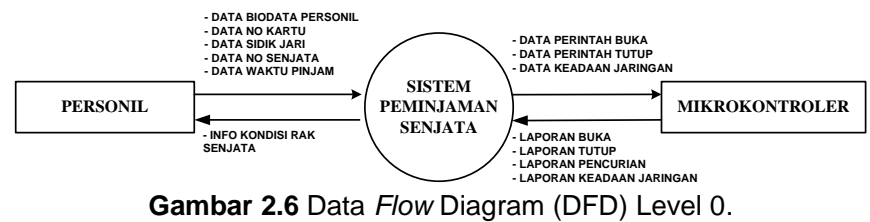

\section{Pengujian dan Analisis}

Data analisa pada pengujian rangkaian driver motor ditunjukkan dalam Tabel 4.2.

Tabel 3.1 Hasil Pengujian V Out Dan Arah Putaran Motor.

\begin{tabular}{|l|l|l|l|}
\hline $\mathrm{A}$ & $\mathrm{B}$ & V out & Arah putaran motor \\
\hline 0 & 0 & $0 \mathrm{~V}$ & Diam \\
\hline 0 & 1 & $11,82 \mathrm{~V}$ & Kiri \\
\hline 1 & 0 & $11,82 \mathrm{~V}$ & Kanan \\
\hline 1 & 1 & $49,9 \mathrm{mV}$ & Diam \\
\hline
\end{tabular}

Analisa yang didapat dari pengujian driver yaitu motor akan berputar ketika kabel inputan pada motor diberikan arus listrik terbalik. Sehingga sangat baik untuk buka dan tutup pengunci rak senjata[21][22].

Tujuan pengujian untuk RS-232 yaitu untuk mengetahui kerja dari alat tersebut, antara keluaran dan masukan haruslah beda tegangan, minus dan tegangan normal.

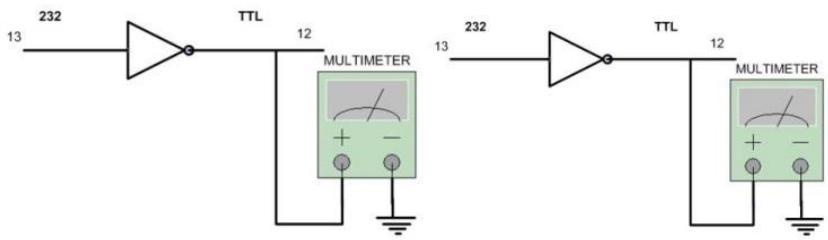

Gambar 3.1 Pengujian RS-232.

Data analisa pada pengujian rangkaian RS-232 ditunjukkan dalam Tabel 4.3.

Tabel 3.2 Hasil Pengujian RS-232.

\begin{tabular}{|c|c|c|}
\hline No & Terminal (Port) & Vo (Volt) \\
\hline 1 & 12 & 4,8 \\
\hline 2 & 13 & $-5,5$ \\
\hline
\end{tabular}

Analisa data dari tabel yaitu pengubah data menjadi serial berhasil dengan baik.

Pada pengujian komunikasi ini menggunakan software Hyperterminal, yaitu dengan cara manual menggunakan huruf yang sudah disesuaikan pada perjanjian dengan software[23].

Tabel 3.3 Daftar Kode Data Komunikasi Jaringan. 


\begin{tabular}{|r|l|c|l|c|}
\hline No & Tombol & $\begin{array}{c}\text { Huruf } \\
\text { Balik }\end{array}$ & \multicolumn{1}{|c|}{ Fungsi } & Keterangan \\
\hline 1 & $\mathrm{t}$ & $\mathrm{t}$ & Ping Jaringan & $\begin{array}{c}\text { Lampu kedip } \\
\text { biru }\end{array}$ \\
\hline 2 & $\mathrm{~b}$ & $\mathrm{~b} / \mathrm{d}$ & Buka/tutup & Togle \\
\hline 3 & $\mathrm{~d}$ & $\mathrm{~d}$ & Tutup paksa & Satu kali \\
\hline 4 & $\mathrm{c}$ & $\mathrm{b}$ & Buka paksa & Satu kali \\
\hline 5 & Limit switch & $\mathrm{p}$ & Kode pencurian & Alarm bunyi \\
\hline
\end{tabular}

Pada pengujian bagian ini, untuk membuktikan bahwa jaringan yang digunakan sebagai jembatan terkoneksi dengan baik. Hasilnya terhubung baik atau tidak bisa juga dilihat pada lampu indicator[24].

Untuk menjaga kerahasian data yang ada dalam database maka admin diwajibkan untuk mengisi username dan password.

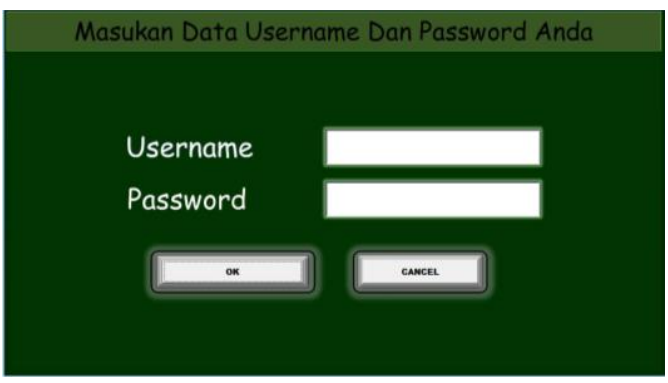

Gambar 3.2 Form Pertama Ketika Dijalankan.

Jika terjadi kesalahan dalam memasukkan username dan password maka akan muncul tampilan yang ditunjukkan dalam Gambar 4.5.

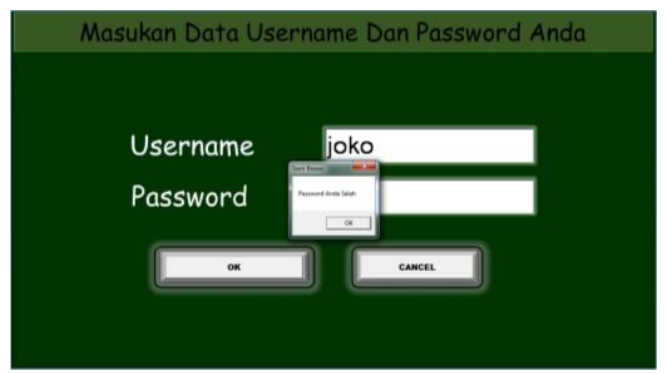

Gambar 3.3 Tampilan Pada Saat Login Salah.

Jika admin memasukkan username dan password dengan benar maka akan muncul tampilan yang ditunjukkan dalam Gambar 4.6.

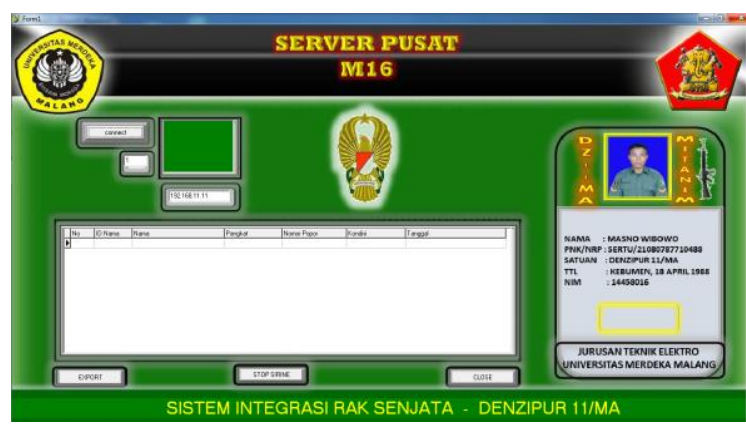


Gambar 3.4 Tampilan pada saat Login benar.

Data analisa pada proses login dapat ditunjukkan dalam Tabel 4.5.

Tabel 3.4 Hasil Pengujian Pada Proses Login.

\begin{tabular}{|l|l|l|l|l|l|l|l|}
\hline $\begin{array}{l}\text { Tomb } \\
\text { ol }\end{array}$ & $\begin{array}{l}\text { Jumlah } \\
\text { Percobaa } \\
\mathrm{n}(\mathrm{x})\end{array}$ & $\begin{array}{l}\text { Berha } \\
\text { sil }\end{array}$ & $\begin{array}{l}\text { Gag } \\
\text { al }\end{array}$ & $\begin{array}{l}\text { Persentase } \\
\text { Keberhasila } \\
\mathrm{n}(\%)\end{array}$ & $\begin{array}{l}\text { Persentas } \\
\text { e } \\
\text { Kegagala } \\
\mathrm{n}(\%)\end{array}$ & $\begin{array}{l}\text { Jumla } \\
\text { h } \\
\text { Recor } \\
\mathrm{d}\end{array}$ & $\begin{array}{l}\text { Keterang } \\
\text { an }\end{array}$ \\
\hline Login & 100 & 100 & - & 100 & 0 & 100 & $\begin{array}{l}\text { Berjalan } \\
\text { dengan } \\
\text { baik }\end{array}$ \\
\hline $\begin{array}{l}\text { Log } \\
\text { out }\end{array}$ & 100 & 100 & - & 100 & 0 & 100 & $\begin{array}{l}\text { Berjalan } \\
\text { dengan } \\
\text { baik }\end{array}$ \\
\hline
\end{tabular}

Data analisa yang diperoleh dari pengujian login diatas dapat disimpulkan bahwa semua tombol perintah pada proses login dapat berfungsi dengan persentase keberhasilan $100 \%$.

Setelah admin memasukkan username dan password secara benar maka admin bisa masuk ke server utama. Setiap ada anggota yang mengambil dan mengembalikan senjata akan tercatat pada tabel di form utama, urutan daftar menurut waktu pengambilan dan pengembalian[25].

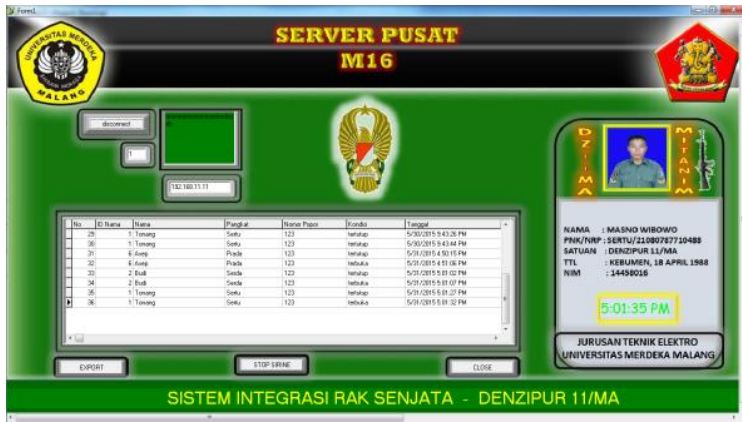

Gambar 3.5 Form Pengambilan dan Pengembalian Senjata.

Jika terjadi pengambilan secara paksa sirine akan berbunyi, dan untuk mematikannya klik "STOP SIRINE". Setelah semua anggota mengembalikan senjata untuk membuat laporan maka klik "EXPORT" kemudian muncul tampilan informasi yang ditunjukkan dalam Gambar 4.8

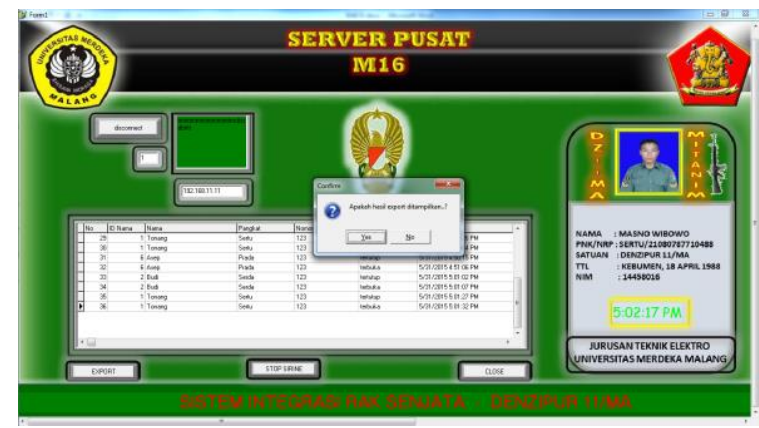

Gambar 3.6 Tampilan Informasi Export.

Kemudian muncul pertanyaan "Apakah hasil export ditampilkan?" klik "OK" muncul pertanyaan lagi "Hasil ditampilkan" klik "OK" maka data pengambilan dan pengembalian senjata muncul dalam bentu MS Excel.

\section{Simpulan}


Pada jarak kurang dari $4 \mathrm{~cm}$ RFID dapat terbaca oleh reader dengan persentase keberhasilan $100 \%$ sehingga pada saat membuka rak senjata dengan mendekatkannya saja atau menempelkan kartu. Ketika ID card berada pada jarak lebih dari $4 \mathrm{~cm}$, reader tidak bisa membaca. Begitu juga apabila kartu dalam keadaan kotor, tergores, basah atau dilengkungkan RFID pada jarak kurang dari $4 \mathrm{~cm}$ tetap terbaca dengan persentase keberhasilan $100 \%$.

Begitu juga dengan sidik jari dalam keadaan bersih, setelah melakukan percobaan sebanyak 10 kali dapat diambil kesimpulan bahwa sidik jari bisa terbaca oleh sensor sebagai kunci dari buka dan tutup rak senjata dengan persentase keberhasilan $70 \%$. Sedangkan sidik jari dalam keadaan kotor untuk terbaca oleh sensor persentase keberhasilannya $0 \%$

\section{References}

[1] H. H. G. Handoll, T. E. Howe, and R. Madhok, "The Cochrane database of systematic reviews," Physiotherapy. 2002.

[2] I. Mujahidin, S. H. Pramono, and A. Muslim, "5.5 Ghz Directional Antenna with 90 Degree Phase Difference Output," 2018.

[3] C. A. Balanis, Modern antenna handbook. 2007.

[4] C. E. Balanis, "Antenna Theory: Analysis and Design, 3rd Edition - Constantine A. Balanis," Book. 2005.

[5] J. Lasmono, A. P. Sari, E. Kuncoro, and I. Mujahidin, "Optimasi Kerja Peluncur Roket Pada Robot Roda Rantai Untuk Menentukan Ketepatan Sudut Tembak," JASIEK (Jurnal Apl. Sains, Informasi, Elektron. dan Komputer), 2019.

[6] C. Bell, Beginning sensor networks with Arduino and Raspberry Pi. 2013.

[7] I. Mujahidin, R. Yuwono, and A. Mustofa, "Rancang Bangun Rectifier Antenna Mikrostrip Ufo Pada Frekuensi Ultra Wideband (Uwb) Sebagai Pemanen Energi Elektromagnetik," J. Mhs. TEUB, vol. 3, no. 2, 2015.

[8] P. S. Arinda, D. J. D. H. Santjojo, M. Masruroh, and S. P. Sakti, "Stability of Polystyrene Film Surface Wettability Modified Using Oxygen Plasma," Mater. Today Proc., vol. 13, pp. 24-29, 2019.

[9] S. K. Sugiarto, I. Mujahidin, and A. B. Setiawan, "2, $5 \mathrm{GHz}$ Antena Mikrostrip Polarisasi Circular Model Patch Yin Yang untuk Wireless Sensor," JEECAE (Journal Electr. Electron. Control. Automot. Eng., vol. 4, no. 2, pp. 297-300, 2019.

[10] S. Laroche, "Polarimetric Doppler weather radar: principles and applications," Atmos. Res., 2002.

[11] B. F. Hidayatulail and I. Mujahidin, "Potential Of 77, $78 \mathrm{~mW}$ Red Diode Laser For Photodynamic," JEEMECS (Journal Electr. Eng. Mechatron. Comput. Sci., vol. 2, no. 2, 2019.

[12] L. M. Argentim, W. C. Rezende, P. E. Santos, and R. A. Aguiar, "PID, LQR and LQR-PID on a quadcopter platform," in 2013 International Conference on Informatics, Electronics and Vision, ICIEV 2013, 2013.

[13] I. Mujahidin and B. F. Hidayatulail, "2.4 GHz Square Ring Patch With Ring Slot Antenna For Self Injection Locked Radar," JEEMECS (Journal Electr. Eng. Mechatron. Comput. Sci., vol. 2, no. 2, 2019.

[14] M. Alaa, A. A. Zaidan, B. B. Zaidan, M. Talal, and M. L. M. Kiah, "A review of smart home applications based on Internet of Things," Journal of Network and Computer Applications. 2017.

[15] R. Yuwono, I. Mujahidin, A. Mustofa, and Aisah, "Rectifier using UFO microstrip antenna as electromagnetic energy harvester," Adv. Sci. Lett., 2015.

[16] K. F. Mak, K. He, J. Shan, and T. F. Heinz, "Control of valley polarization in monolayer MoS2 by optical helicity," Nat. Nanotechnol., 2012.

[17] I. Mujahidin, "Directional $1900 \mathrm{MHz}$ Square Patch Ring Slot Microstrip Antenna For WCDMA," JEEMECS (Journal Electr. Eng. Mechatron. Comput. Sci., 2019.

[18] M. A. Khan and K. Salah, "IoT security: Review, blockchain solutions, and open challenges," Futur. Gener. Comput. Syst., 2018.

[19] A. Al-Fuqaha, M. Guizani, M. Mohammadi, M. Aledhari, and M. Ayyash, "Internet of Things: A Survey on Enabling Technologies, Protocols, and Applications," IEEE Commun. Surv. Tutorials, 2015.

[20] I. Mujahidin and P. S. Arinda, "Antena Compact Double Square Marge 2, 6GHz Dengan Output Perbedaan Fase 90 Derajat Untuk Aplikasi LTE," JEECAE (Journal Electr. 
Electron. Control. Automot. Eng., vol. 4, no. 2, pp. 273-278, 2019.

[21] W.-H. Steeb, "Fuzzy Sets and Fuzzy Logic," in The Nonlinear Workbook, 2012.

[22] T. A. S, A. Rabi', D. Minggu, and I. Mujahidin, "Frequency Hopping Video Real Time Untuk Pengamanan Data Pengintaian Operasi Inteligence TNI," JASIEK (Jurnal Apl. Sains, Informasi, Elektron. dan Komputer), 2019.

[23] M. Abzalov, "Database," in Modern Approaches in Solid Earth Sciences, 2016.

[24] A. Dorri, S. S. Kanhere, R. Jurdak, and P. Gauravaram, "Blockchain for loT security and privacy: The case study of a smart home," in 2017 IEEE International Conference on Pervasive Computing and Communications Workshops, PerCom Workshops 2017, 2017.

[25] M. Y. Galperin and G. R. Cochrane, "Nucleic acids research annual database issue and the NAR online molecular biology database collection in 2009," Nucleic Acids Research. 2009. 